\title{
Local tumour ablation for localized kidney cancer: Practice patterns in Canada
}

\author{
Vincent Trudeau, MD;,1,2 Alessandro Larcher, MD.,1,3 Paolo Dell'Oglio, MD ${ }^{-1,3}$ Katharina Boehm, MD ${ }^{-1,4}$ \\ Mohamed Bishr, MD, ${ }^{1,2}$ Pierre I. Karakiewicz, MD ${ }^{1,2}$
}

'Cancer Prognostics and Health Outcomes Unit, University of Montreal Health Centre, Montreal, Canada; ${ }^{2}$ Department of Urology, University of Montreal Health Centre, Montreal, Canada; ${ }^{3}$ Division of Oncology, Unit of Urology, URI, IRCCS Ospedale San Raffaele, Milan, Italy; ${ }^{4}$ Martini-Clinic, Prostate Cancer Centre Hamburg-Eppendorf, Hamburg, Germany

Cite as: Can Urol Assoc J 2015;9(11-12):420-3. http://dx.doi.org/10.5489/cuai.3317

Published online December 14, 2015

\section{Abstract}

Introduction: Local tumour ablation (LTA) is a recommended option for the treatment of localized kidney cancer in nonsurgical candidates. We performed a survey to describe the practice patterns of this procedure in Canada.

Methods: An electronic survey was sent by email to all urologists registered to the Canadian Urological Association (CUA). Urologists were queried about general demographic information, LTA availability at their institution (and reasons for non-availability, if it was the case), as well as the type and context of LTA use.

Results: Overall, 103 individual responses were obtained (response rate of $19.5 \%)$. Of those, $58(56.3 \%)$ had access to LTA at their institution. Urologists who had access to LTA were more likely to work at an academic institution (69 vs. 16\%, p<0.001). Among individuals who did not use LTA, the main reasons were lack of staff, such as radiologists, who can assist and/or perform the procedure (64\%); and lack of expertise with the procedure $(62 \%)$. Among urologists who had access to LTA, percutaneous radiofrequency and cryoablation were the most commonly used $(72 \%$ and $21 \%$, respectively); however, urologists were rarely involved in those procedures (12\%).

Conclusions: In this national survey, we found that a significant proportion of Canadian urologists did not have access to LTA. We also found that when LTA was performed, urologists were rarely involved in the procedures. Those findings represent significant areas for improvement in the access to LTA. The conclusions of this study are limited by the low response rate.

\section{Introduction}

Different management options are available in the treatment of small and localized kidney cancer for nonsurgical candidates. ${ }^{1-4}$ Among those management options, LTA may be undertaken and, according to recent reports, provide adequate oncological outcomes. ${ }^{5,6} \mathrm{Also}$, different LTA types of energy (for example, cryoablation, radiofrequency, or microwaves) and approaches (percutaneous, laparoscopic, or open) can be chosen depending on the institution's experience.

In the current Canadian context, information on LTA access and practice patterns is lacking. In order to address this void in the current literature, we performed a national survey among practicing urologists to assess current LTA practice patterns in Canada. Specifically, we sought to describe the current context of LTA use and to identify potential barriers to LTA access.

\section{Methods}

Starting in April 2015, a survey link was sent by email to all practicing urologists registered to the CUA via the association's email system. Specifically, 529 urologists were queried. To increase response rate, the email was sent a total of four times and two cash prizes were offered randomly among respondents. When there was more than one answer by the same individual, the first answer was kept. After the prize draw, all email and IP address were deleted to assure confidentiality.

The survey contained a total of six to 15 questions, depending of the urologists' answers. The survey's format was inspired by two recently published surveys on LTA in the U.S. ${ }^{7,8}$ and consisted of three different sections. The first set of questions described the practice context of each urologist; for instance, hospital province, academic status, and partial nephrectomy volume per month were detailed. The second part assessed whether LTA was available at participants' centre. If LTA was not available at the respondent's centre, the respondent was asked to explain why. The third part focused on the type and context of LTA use among respondents. Specifically, information on the number of procedures per month, the type of energy and approach, the maximum tumor size amenable to LTA, the role of the urologists in percutaneous LTA, the type of imaging technology used, as well as biopsy type and timing were all recorded. Most questions were multiple choice, but open-ended questions were also used. 
Results were shown in frequencies and proportions. Chi-square was used to assess potential differences among groups. Statistical analyses were performed using RStudio ${ }^{7}$ (version 0.98). All test were two-sided and statistical significance was set to $p<0.05$.

\section{Results}

Overall, 103 individual responses were obtained (response rate of $19.5 \%)$. Of those, $58(56.3 \%)$ had access to LTA at their institution. General characteristics are available in Table 1.

Urologic surgeons who had access to LTA at their centres were more likely to work at an academic institution (69 vs. $16 \%, \mathrm{p}<0.001)$ and more likely to have a high partial nephrectomy volume in their centre $(52 \%$ vs. $13 \%$ with more than five partial nephrectomies per month, $\mathrm{p}<0.001$ ). Interestingly, we did not record a statistically significant difference in the access to LTA among different provinces. It is of note that several provinces had too few respondents to perform meaningful analyses; six provinces and territories had less than five answers.

Among individuals who did not have access to LTA, the main reasons were lack of staff, such as radiologists, who can assist and/or perform the procedure (64\%); and lack of expertise with the procedure $(62 \%$, Table 2$)$. Moreover, several urologists $(16 \%)$ stated they did not have enough funding and/or material resources at their institution to offer LTA. Of all participants, $11 \%$ reported having access to LTA via referral to a nearby centre.

\begin{tabular}{|c|c|c|c|}
\hline & $\begin{array}{c}\text { No LTA } \\
(n=45)\end{array}$ & $\begin{array}{c}\text { LTA } \\
(n=58)\end{array}$ & $p$ value \\
\hline $\begin{array}{l}\text { Academic centre } \\
\text { No } \\
\text { Yes }\end{array}$ & $\begin{array}{l}38(84) \\
7(16)\end{array}$ & $\begin{array}{l}18(31) \\
40(69)\end{array}$ & $<0.001$ \\
\hline $\begin{array}{l}\text { PN volume/month in centre } \\
0-5 \\
6-10 \\
>10\end{array}$ & $\begin{array}{c}39(87) \\
5(11) \\
1(2)\end{array}$ & $\begin{array}{l}28(48) \\
21(36) \\
9(16)\end{array}$ & 0.002 \\
\hline $\begin{array}{l}\text { Province } \\
\text { Alberta } \\
\text { British Columbia } \\
\text { Manitoba } \\
\text { New Brunswick } \\
\text { Newfoundland and Labrador } \\
\text { Northwest Territories } \\
\text { Nova Scotia } \\
\text { Ontario } \\
\text { Quebec } \\
\text { Saskatchewan } \\
\text { Unknown }\end{array}$ & $\begin{array}{l}2(4) \\
7(16) \\
3(7) \\
2(4) \\
2(4) \\
1(2) \\
1(2) \\
24(53) \\
3(7) \\
0(0) \\
0(0)\end{array}$ & $\begin{array}{c}6(10) \\
10(17) \\
1(2) \\
0(0) \\
1(2) \\
0(0) \\
1(2) \\
21(36) \\
15(26) \\
2(3) \\
1(2)\end{array}$ & 0.08 \\
\hline
\end{tabular}

LTA: local tumour ablation; PN: partial nephrectomy.
The remaining analyses focused on respondents who had access to LTA at their institution. All the characteristics of LTA experience are displayed in Table 3.

When urologists had to decide on the maximum tumour size amenable to LTA, $26 \%$ and $45 \%$ reported a cut-off of $3 \mathrm{~cm}$ and $4 \mathrm{~cm}$, respectively. Regarding type of energy used at percutaneous LTA, $21 \%$ and $72 \%$ reported using percutaneous cryoablation and radiofrequency, respectively. At percutaneous procedures, only one urologist performed such treatments alone (2\%). Conversely, most percutaneous LTA were performed by radiologists $(88 \%)$, or both urologist and radiologist $(10 \%$, Table 4$)$. Urologists seldom placed the ablation needle themselves at LTA $(8 \%)$, or were rarely present during the procedure $(10 \%)$. However, most urologists provided postoperative care of LTA patients $(85 \%)$. Of urologists with access to LTA at their institution, $9 \%$ and $7 \%$ used laparoscopic cryoablation and radiofrequency, respectively.

Several observations were made regarding imaging and biopsy at LTA. LTA was commonly performed with the combination of computed tomography and sonography (43\%), followed by computed tomography guidance alone (31\%). At laparoscopic LTA, perioperative sonography was used at most institutions (86\%).

Renal mass biopsy was performed at LTA at most institutions (84\%). In $36 \%$ and $52 \%$ of the respondent institutions, the renal mass biopsies were done before or during the procedure, respectively.

Finally, core biopsy (69\%), followed by the combination of core biopsy and fine needle aspiration (12\%) were the most common procedures seen.

\section{Discussion}

LTA is a recommended treatment for localized kidney cancer in nonsurgical candidates. ${ }^{1-4}$ However, little is known about current LTA practice patterns in Canada. In this light, we sought to examine those practice patterns among urologists.

We performed a national survey among all Canadian urologists registered to the CUA and found that a significant proportion of urologists (43.7\%) did not have access to LTA at

\begin{tabular}{|c|c|}
\hline Reasons for lack of access to LTA & $\mathbf{N}(\%)$ \\
\hline $\begin{array}{l}\text { Lack of sufficient data to prove efficacy of the ablation } \\
\text { procedures }\end{array}$ & $5(11)$ \\
\hline Lack of expertise to do the procedure & $28(62)$ \\
\hline $\begin{array}{l}\text { Lack of staff (interventional radiologist, etc.) who can } \\
\text { assist and/or perform the procedure }\end{array}$ & $29(64)$ \\
\hline \multicolumn{2}{|l|}{ Other } \\
\hline Available at another centre via referral & $5(11)$ \\
\hline Lack of funding/material to perform LTA & $7(16)$ \\
\hline LTA: local tumour ablation. & \\
\hline
\end{tabular}


Trudeau et al.

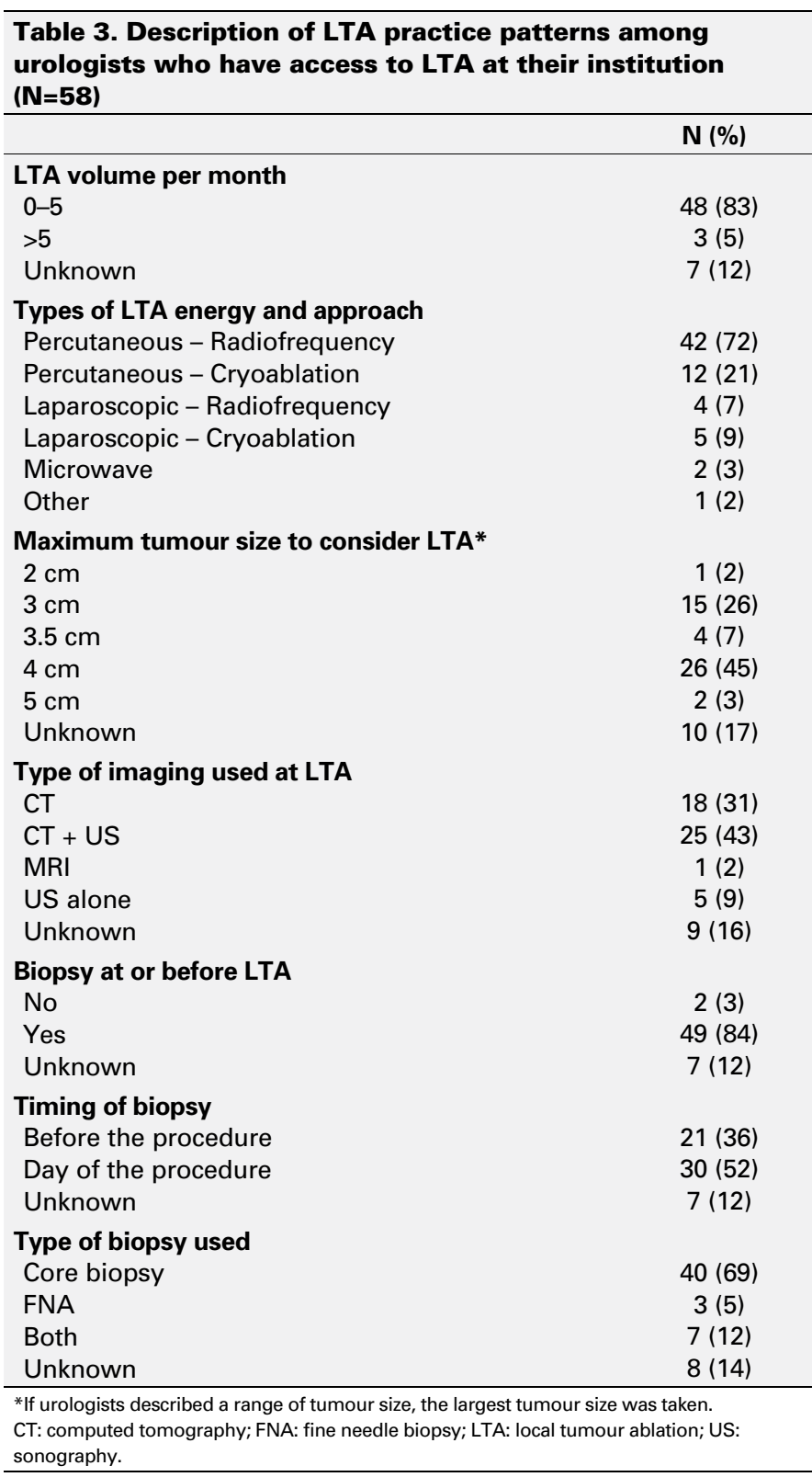

their institutions. Urologists who did not have access to LTA were more likely practicing at non-academic, small surgical volume centres. We recorded that the main reasons for the absence of access was the lack of staff $(64 \%)$ or the lack of expertise $(62 \%)$ to do the procedure. Also, several urologists $(16 \%)$ did not have the financial and/or material resources at their institution to offer LTA. Those findings are worrisome, as they represent barriers to potential options of care.

This information can be seen as motivation to improve access to nonsurgical management of kidney cancer. For instance, emphasis should be placed on better funding this type of technology. Similarly, fellowship training should be encouraged. Despite lack of urological expertise with LTA, several urologists $(11 \%)$ have access to LTA through referral

\begin{tabular}{lc}
\hline $\begin{array}{l}\text { Table 4. Description of urologist involvememt in } \\
\text { percutaneous LTA (N=48) }\end{array}$ \\
\hline
\end{tabular}

to another centre. Such practice should be encouraged to maximise access to LTA in Canada.

We also found that urologists were rarely directly involved in percutaneous procedures. Specifically, urologists performed percutaneous LTA alone or with the radiologist in only $2 \%$ and $10 \%$ of percutaneous LTA, respectively. These results differ from the U.S. context, in which urologists are more likely to be actively involved. In a survey of U.S. academic institutions, Patel et al. found that $55 \%$ of urologists were involved in percutaneous LTA. ${ }^{8}$ Potential use of laparoscopic LTA could reverse this trend by virtue of placing the technology in urologists' hands.

It is encouraging to see that most of the urologists' institutions perform renal bass biopsy at or prior to LTA (84\%). Moreover, the core biopsy (alone or with combination with fine needle aspiration) is used in most cases (81\%). Those findings parallel current Canadian guidelines and expert opinions, which strongly support the role of biopsy at or prior to LTA. ${ }^{4}$

Interestingly, $36 \%$ and $52 \%$ of patients undergo renal mass biopsy before or on the day of the procedure, respectively. Ideally, biopsy prior to the procedure could better guide the treatment choice. For example, renal masses with favourable histology could be observed instead of being subjected to LTA. However, use of pre-procedure biopsy requires an additional visit for the patient and includes administration of anesthesia. Consequently, institution-specific protocols should ideally be implemented to optimize patient management and treatment efficacy.

Our survey is not the first to address this topic in the North American context, but it is the first to focus on Canadian practice patterns. ${ }^{8,9}$ In the most recent survey of American academic centres, Patel et al found that LTA was available at all academic centres (compared to $85.1 \%$ of academic centres in our study). ${ }^{8}$ They also reported that most centres had access to laparoscopic cryoablation (83\%) or laparoscopic radiofrequency (20\%). This contrasts with low access rates to laparoscopic cryoablation $(9 \%)$ or radiofrequency $(7 \%)$ in Canada. The low access rates are surprising, as these treatments showed excellent oncological outcomes at ter- 
tiary care centres. ${ }^{5}$ The discrepancies between access and outcome further highlight the need for training and expertise acquisition, as well as implementation of healthcare pathways.

Our study is not without limitations. The main one resides in the low response rate $(19.5 \%)$. This response is lower than the one reported by Bandi et al $(62 \%)^{9}$ and the one reported by Patel et al $(52 \%)^{8}$ in similar surveys from the U.S. However, in those cases, the survey was sent directly to all academic centres, thus not comprising other types of practices. In contrast, our survey was sent to all practicing urologists registered to the $\mathrm{CUA}$, which render our results more generalizable. Moreover, our response rate parallels a previous Canadian survey on small renal masses, in which an $18 \%$ response rate was obtained. ${ }^{10}$

Nevertheless, our results should be interpreted with caution and cannot be extrapolated to all Canadian practicing urologists. It may also be possible that a response bias toward those who had access to LTA in their institution is operational. In this context, further studies are needed to confirm our findings.

Finally, since the survey was designed to be short and ensure optimal response rate, additional information on other types of nonsurgical management used (such as observation) were not evaluated. Despite those limitations, this report describes, for the first time, the actual LTA context in Canada and provides potential aims of improvement in the access to LTA.

\section{Conclusions}

In this national survey, we found that a significant proportion of Canadian urologists did not have access to LTA. We also found that when LTA was performed, urologists were rarely involved in the procedures. These findings represent significant areas for improvement in the access to LTA. The conclusions of this study are limited by the small response rate.

Competing interests: The authors declare no competing financial or personal interests.

This paper has been peer-reviewed.

\section{References}

1. Liungberg B, Bensalah K, Canfield S, et al. EAU Guidelines on Renal Cell Carcinoma: 2014 Update. Eur Urol 2015;67:913-24. http://dx.doi.org/10.1016/i.eururo.2015.01.005

2. Novic $A C$, Campbell SC, Belldegrun A, et al. Guideline for management of the clinical stage 1 renal mass, 2009, updated in 2010. http://www.auanet.org/education/guidelines/renal-mass.cfm. Accessed November 11, 2015

3. NCCN Clinical Practice Guidelines in Oncology: Kidney Cancer 2014:1-50. http://www.nccn.org. Accessed November 11, 2015.

4. Jewett MAS, Rendon R, Lacombe L, et al. Canadian Guidelines for Management of the Small Renal Mass (SRM), April 2015. http://www.cua.org/themes/web/assets/files/smr_guideline_board_ approved_27_04_2015.pdf. Accessed November 14, 2015.

5. Larcher A, Fossati N, Mistretta F, et al. Long-term oncologic outcomes of laparoscopic renal cryoablation as primary treatment for small renal masses. Urol Oncol 2015;33:e21-9. http://dx.doi.org/10.1016/i. urolonc.2014.09.003

6. Lorber $G$, Glamore $M$, Doshi $M$, et al. Long-term oncologic outcomes following radiofrequency ablation with real-time temperature monitoring for Tla renal cell cancer. Urol Oncol 2014;32:1017-23. http:// dx.doi.org/10.1016/i.urolonc.2014.03.005

7. http://www.rstudio.com. 2014; http://www.rstudio.com. Accessed November 14, 2015.

8. Patel SR, Abel EJ, Hedican SP, et al. Ablation of small renal masses: practice patterns at academic institutions in the United States. J Endourol 2013;27:158-61. http://dx.doi.org/10.1089/end.2012.0381

9. Bandi G, Hedican SP, Nakada SY. Current practice patterns in the use of ablation technology for the management of small renal masses at academic centers in the United States. Urology 2008;71:113-7. http://dx.doi.org/10.1016/j.urology.2007.08.023

10. Millman AL, Pace KT, Ordon M, et al. Surgeon-specific factors affecting treatment decisions among Canadian urologists in the management of ptla renal tumours. Can Urol Assoc J 2014;8:183-9. http://dx.doi. org/10.5489/cuaj.1884

Correspondence: Dr. Vincent Trudeau, Cancer Prognostics and Health Outcomes Unit, University of Montreal Health Centre, 264 Blvd. René-Lévesque East, Suite 228, Montreal, Québec, H2X IPI; Email: vincent.trudeau.1@umontreal.ca 